\title{
BEAM SPECIES MIX AS A FUNCTION OF DIII-D NEUTRAL BEAM ION SOURCE OPERATION PARAMETERS
}

by

S.P. RIGGS and R. HONG

$$
\begin{aligned}
& \text { LCENA } \\
& \text { OCT } 1.519 .99 \\
& \text { OS } 11
\end{aligned}
$$

OCTOBER 1993

\section{geNeral atomics}




\section{DISCLAIMER}

This report was prepared as an account of work sponsored by an agency of the United States Government. Neither the United States Government nor any agency thereof, nor any of their employees, makes any warranty, express or implied, or assumes any legal liability or responsibility for the accuracy, completeness, or usefulness of any information, apparatus, product, or process disclosed, or represents that its use would not infringe privately owned rights. Reference herein to any specific commercial product, process, or service by trade name, trademark, manufacturer, or otherwise, does not necessarily constitute or imply its endorsement, recommendation, or favoring by the United States Government or any agency thereof. The views and opinions of authors expressed herein do not necessarily state or reflect those of the United States Government or any agency thereof. 


\section{BEAM SPECIES MIX \\ AS A FUNCTION OF DIII-D \\ NEUTRAL BEAM ION SOURCE \\ OPERATION PARAMETERS}

by

S.P. RIGGS and R. HONG

This is a preprint of a paper to be presented at the 15th IEEE Symposium on Fusion Engineering, October 11-15, 1993, Cape Cod, Massachusetts, and to be printed in the Proceedings.

Work supported by U.S. Department of Energy

Contract DE-AC03-89ER51114

GENERAL ATOMICS PROJECT 3466 OCTOBER 1993

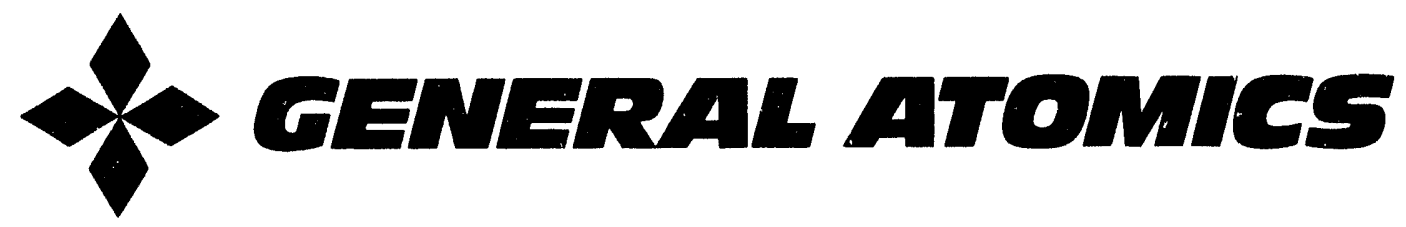




\title{
BEAM SPECIES MIX AS A FUNCTION OF DIII-D NEUTRAL BEAM ION SOURCE OPERATION PARAMETERS
}

\author{
S.P. Riggs and R. Hong \\ General Atomics \\ P.0. Box 85608, San Diego, California 92186-9784
}

\begin{abstract}
By measuring the Balmer-alphe emission for deuterium, Doppler-shifted spectroscopy (DSS) can give relative fractions of the ions $\mathrm{D}+, \mathrm{D} 2+, \mathrm{D} 3+$ (species mix) produced by the DIII-D neutral beam ion sources. The species mix varies with beam energy, arc power, gas flow rate, and time within a beam puloe. The full energy species fraction gets larger and tenda to become constant with increasing beam energy while the third energy species tends to decrease. Varying the neutraliver flow rate between 0 and 20 torr- $l /$ sec causes the full energy species fraction to decrease by $\sim 0.04$ in favor of more third energy particles. Measurements made at various times within a beam pulse showed that the species fraction normally varies by about 0.02 but can have a variation of as much as 0.14 . The effect of the beam parameters on the species mix varies slightly between lon sources. Each of the beam species has a different neutralisation efficiency. Thus, the neutral beam power injected into the tokamak depends on the species mix. The neutralisation fraction (and the total injected power) obtained using beam species as measured by DSS at a beam energy of $80 \mathrm{keV}$ is $4 \%$ lower than previously believed. This difference becomes smaller with decreasing beam energy until they converge at $50 \mathrm{keV}$.
\end{abstract}

\section{INTRODUCTION}

Beam species measurements are taken in the region of the neutralizer for earh of the eight ion sources in the DIII-D neutral beam system. The ion sources are arranged in four beam lines, two sources for each beamline. These measurements are made optically by detecting the Balmer-alphe emission of the deuterium ion beam and background gas within the neutralizer cell. The degree to which the beam species changes when various ion source operational parameters are varied is investigated. These parameters include the beam energy, perveance, and the gas flow rate into both the source and the neutralizer. There is also a relatively large variation in the beam species with time.

\section{OVERVIEW OF DATA ANALYSIS}

A typical DSS data scan for a neutral beam shot is shown in Fig. 1. This waveform, taken over an interval of $0.3 \mathrm{sec}$, is a composite of four different sources of Balmeralphe emission from deuterium. (1) The unshifted $D_{\alpha}$ peak is from the background gas in the neutralizer. This excited but unaccelerated gas has two sources, first is

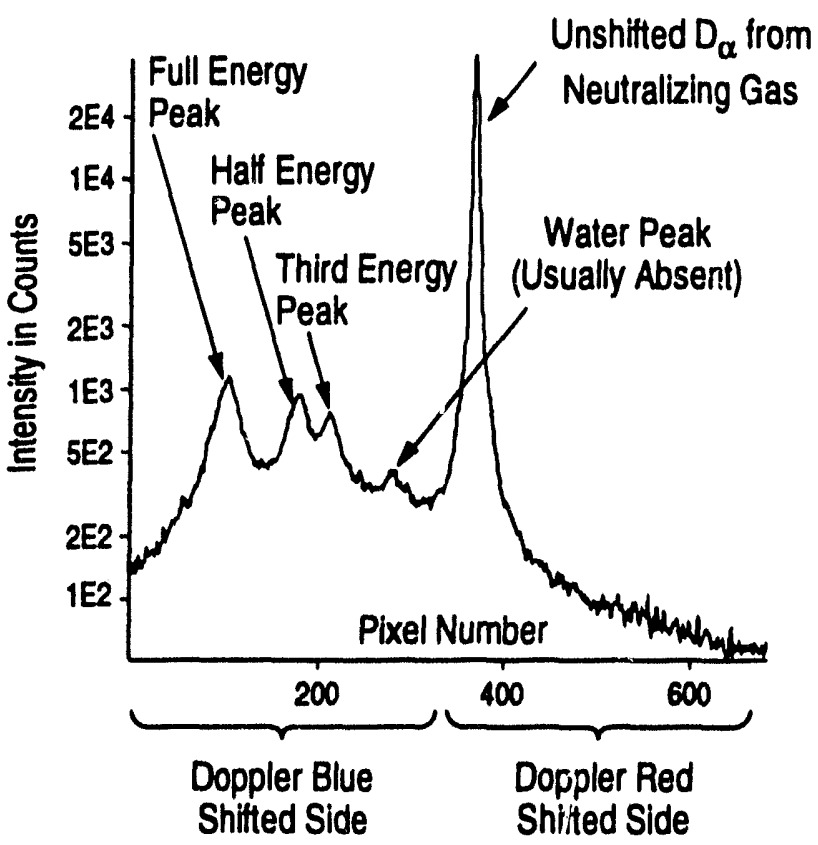

Fig. 1. Typical data taken for beam species measurement. The water peak is usually undetected.

neutral gas coming from the arc chamber and second is from intentional flow of deuterium into the neutralizer cell. (2) There is a small peak due to singly ionired water molecules being accelerated. In the neutralizing process, a hydrogen is stripped from the water molecule and emits this Doppler-shifted $\mathrm{H}_{\alpha}$ signal. (3) The three species peaks are Doppler-shifted by different amounts according to their velocities. Since each of the species was singly ionized while being accelerated, they each have the same kinetic energy. This energy is divided evenly among the nuclei, hence each species has a different speed. (4) There is a large background signal (about 2.0 times the area under the combined species peaks) of highly divergent neutrals.

The width of the individual peaks is due to three factors. These factors are instrumental response, thermal broadening, and divergence of the energetic beam. The beam divergence has an effect on the width that is eight times larger than that of the instrumental response and four times larger than that of thermal broadening. 
Before the analysis begins, the raw data is corrected for detector dark current and individuai pixel sensitivity. The central unshifted $D_{\alpha}$ signal must then be subtracted out of the data because it has a large tail in the region of the species peaks (see Fig. 1). This signal is due to the neutralizing gas $D_{\alpha}$ line being broudened by both the thermal motion of the gas and the instrumental response. Both of these effects are symmetric about the $D_{\alpha}$ line. Thus, the signal can be reflected about the $\mathrm{D}_{\alpha}$ line and subtracted leaving the Doppler-shifted signal from the energetic beam. Hydrogen gas mixed in with the deuterium will throw off this symmetry (the wavelength of $\mathrm{H}_{\alpha}$ is $1.9 \AA$ greater than the wavelength of $D_{\alpha}$ ). So if there is too much $\mathrm{H}_{2}$ or water vapor within the neutralizer cell, then this subtraction is not valid.

Four Gaussians are fitted to the data (the background signal has been demonstrated to be a good fit to a Gaussian) after the central $D_{\alpha}$ subtraction. The fitting subroutine is written in " $\mathrm{C}$ " and uses the LevenbergMarquardt method which requires an initial guess. The guess routine uses a combination of the beam energy for the shot, the values of certain points within the data to be fit, and constants gained by trial and error. Fig. 2 shows a typical fit.

The species mix is now calculated using the three species Gaussians. The species fraction is proportional to $A /\left(\sigma_{\text {eff }}^{*} i\right)[1]$ where $A$ is the area of the Gaussian and $i$ is 1,2 , or 3 , depending on whether the particular species is full energy, half energy, or third energy. Using the thick target approximation, the effective $\mathrm{D}_{\alpha}$ light production cross-section for each species can be written as

$$
\sigma_{\text {eff }}=\left(\sigma_{0}^{\text {roac }} \sigma_{0}^{\text {opt }}+\sigma_{+}^{\text {reac }} \sigma_{+}^{\text {opt }}\right) /\left(\sigma_{0}^{\text {reac }}+\sigma_{+}^{\text {reac }}\right) \text {, }
$$

where

$\sigma_{0}^{\text {reac }}$ is the neutralization cross-section,

$\sigma_{+}^{\text {reac }}$ is the reionization cross-section,

$\sigma_{0}^{\text {opt }}$ and $\sigma_{+}^{\text {opt }}$ are the optical excitation cross-sections.

\section{EFFECTS OF ION SOURCE OPERATIONAL PARAMETERS ON THE BEAM SPECIES}

The species mix varies with beam energy as shown in Fig. 3. This figure shows the consistency of the data collected through two days of operation. As seen in the figure, the full energy species fraction changes by 0.125 over a range of $35 \mathrm{keV}$. The peak-to-peak error is about 0.04 . Fig. 4 shows the beam species when the perveance (defined by the ratio of the extracted beam current to the beam energy) is varied with the beam energy held to $60 \mathrm{keV}$. This results in a change of 0.035 in the full energy species fraction over the $0.28 \mu$ p range in this scan. Fig. 5 shows the full energy species fraction as a function of arc power for both a beam energy scan and a perveance scan for beam energy held at $60 \mathrm{keV}$. It can be seen here that the fractional beam species is a function only of arc power when either the beam energy is varied or the perveance is varied. Note that the peak to peak error

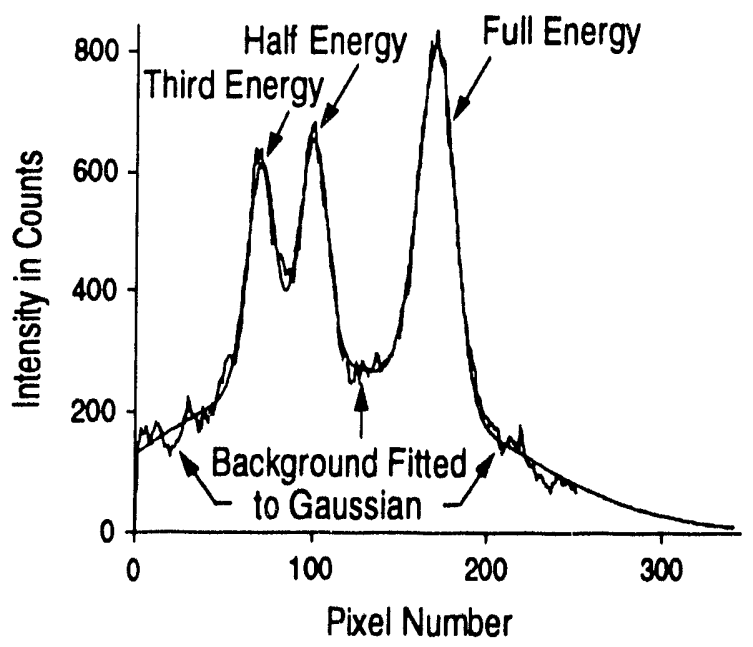

Fic. 2. The data after the central $D_{\alpha}$ subtraction is shown along with three fitted Gaussians representing the three species peaks and a fourth Gaussian fit to the background.

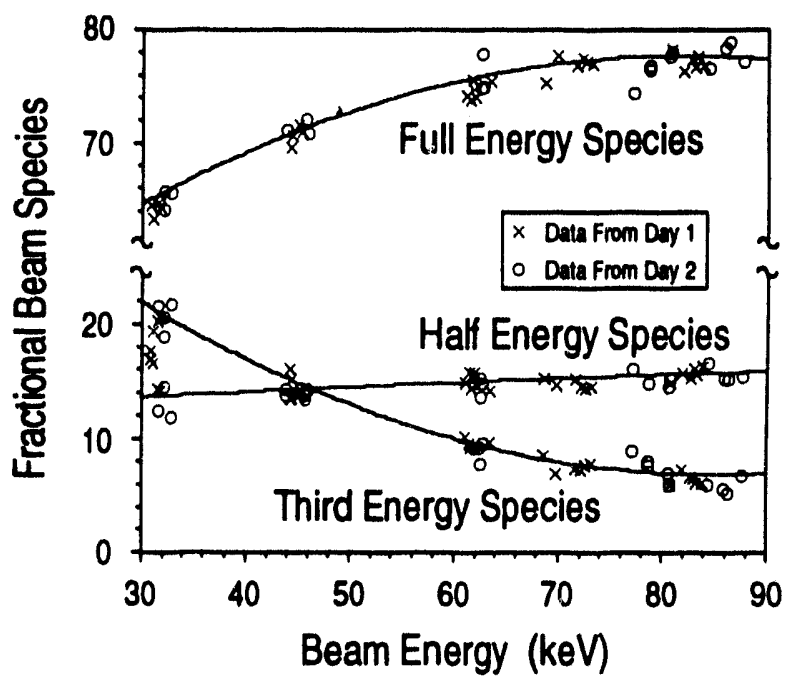

Fig. 3. Beam species as a function of beam energy with the perveance held constant.

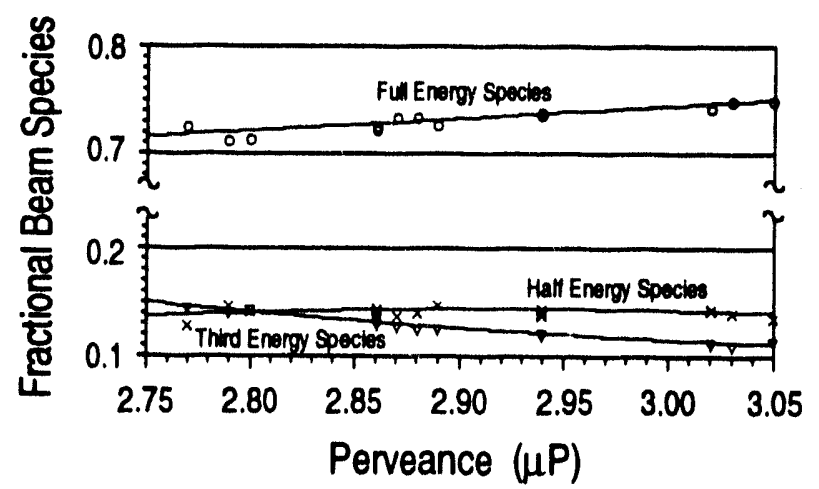

Fic. 4. Beam species as a function of beam perveance with the beam energy held to $60 \mathrm{keV}$. 


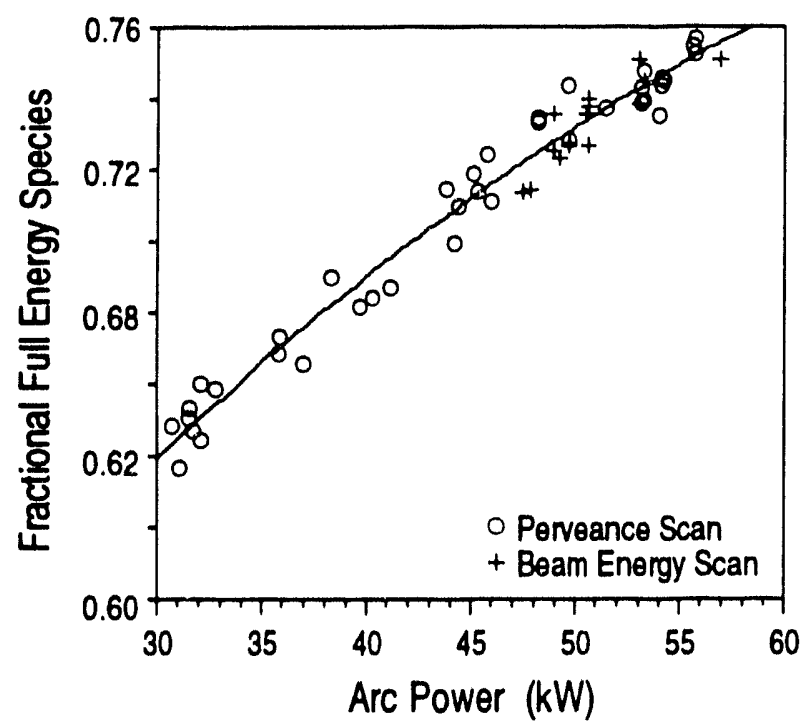

Fic. 5. Full energy species as a function of arc power for both a beam energy scan and a perveance scan.

is about 0.02 in comparison to the 0.04 error found in Fig. 3.

In the scan shown in Fig. 6, the neutralizer gas flow rate was varied from 0 to 20 torr- $\ell / \mathrm{sec}$ (the normal neutralizer gas flow rate is $10 \mathrm{torr}-\ell / \mathrm{sec}$ ). This resulted in a steady decrease of the full energy species fraction of 0.04 over the 20 torr- $\ell / \mathrm{sec}$ range of the scan. In Fig. 7, the source gas flow rate was varied from 20 torr- $\ell / \mathrm{sec}$ (the normal source flow rate) to 30 torr- $\ell / \mathrm{sec}$ (the neutralizer flow rate was held at 10 torr $-\ell / \mathrm{sec}$ ) with a resulting steady decrease of 0.029 in the full energy species fraction. Notice that this is a larger effect than for the variable neutralizer flow for a total gas flow rate change of 10 torr- $\ell / \mathrm{sec}$. The source flow scan was associated with

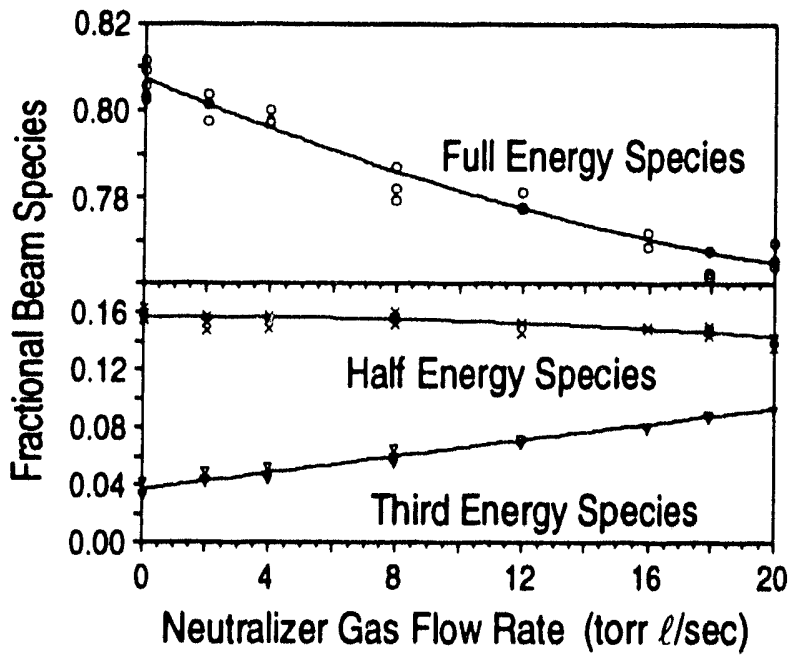

Fig. 6. Beam species as a function of neutralizer gas flow rate with the beam energy held at $75 \mathrm{keV}$ and the source gas flow rate held at 20 torr- $\ell / \mathrm{sec}$.

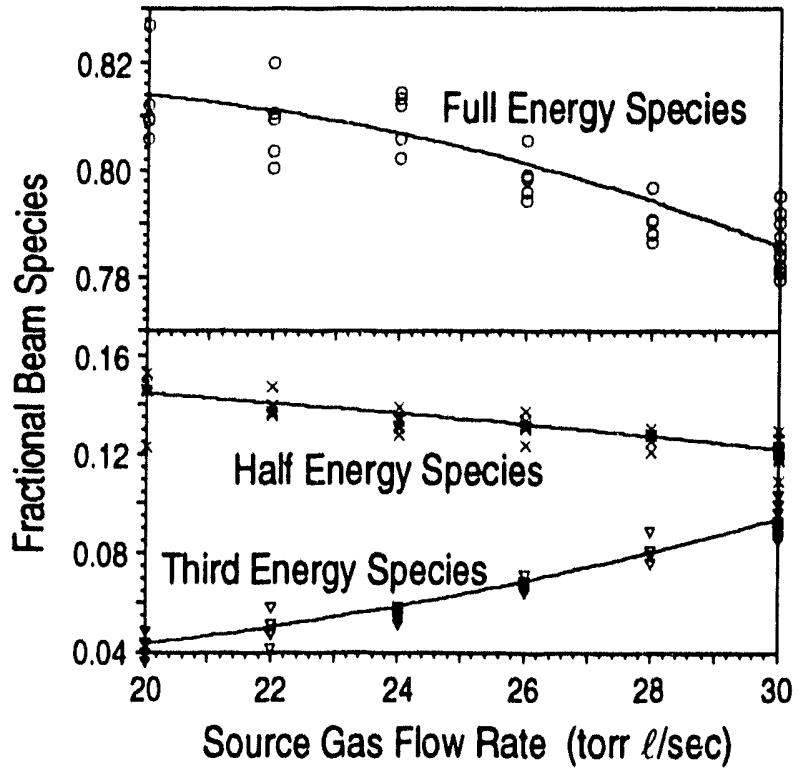

Fra. 7. Beam species as a function of source gas flow rate with the beam energy held at $75 \mathrm{keV}$ and the neutralizer gas flow rate held at 10 torr $-\ell / \mathrm{sec}$.

an arc power change of $4.5 \mathrm{~kW}$. Over the same arc power change at the same beam energy, the full energy species fraction would be expected to change by 0.020 instead of 0.029 . Thus, both the arc power and the gas flow rate will change the beam species.

The beam species mix as a function of time was obtained every $30 \mathrm{msec}$ on shots of $1.2 \mathrm{sec}$ duration (see Fig. 8), and several things are noteworthy. First, there is a slow but steady increase in the full energy species. This is matched by a steady decrease in the third energy species. The second thing of note here is the periodic nature of the beam species with a frequency varying in the neighborhood of $4 \mathrm{~Hz}$. This variation in the full energy species fraction usually has a peak to peak amplitude of about 0.02 but has been observed to be as large as 0.14 as seen here. Finally, even though it is not easily seen here (because of the larger than average amplitude of the periodic signal), the third energy species has an initial sudden decrease (from about 0.07 down to 0.05 ) within the first $120 \mathrm{msec}$. This initial decrease seems to be independent of the magnitude of the species oscillation.

Data has also been taken within the drift duct which links the beamline and the DIII-D tokamak. The background portion of the signal has decreased by a factor of 7.1 in relation to the species. Thus, the background contribution to the signal in the neutralizer is from highly divergent ions which are scraped off by successive collimators within the beamline. The beam species as measured in the drift duct is comparable to that measured in the neutralizer. The full energy species fraction, as measured in the neutralizer, is within 0.007 of the measurements made in the drift duct. This justifies the use of the thick target approximation for our normal gas flow rates. 


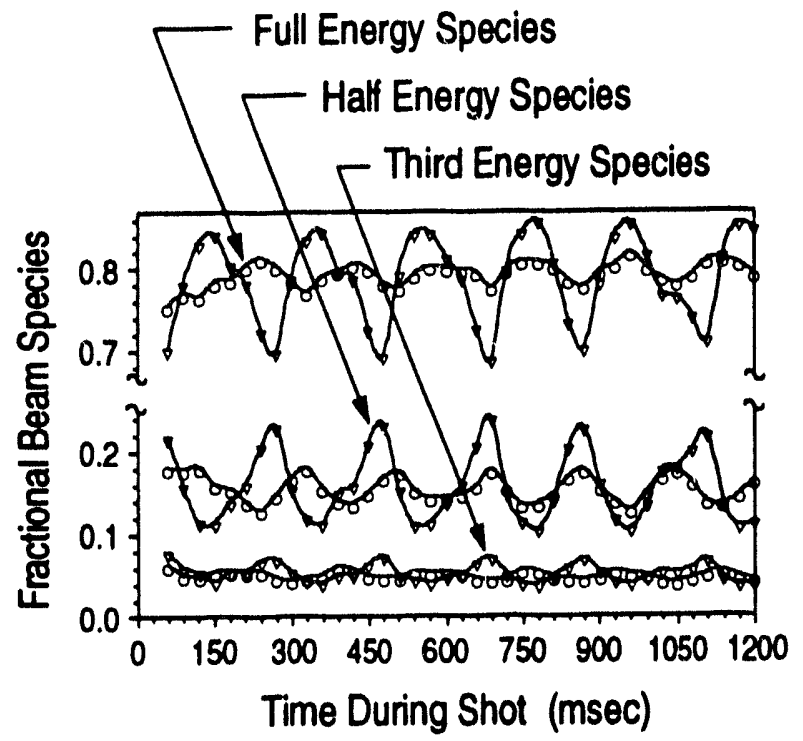

Fic. 8. The time evolution of the beam species for two shots is shown. The oscillations of these two shots are larger than the more common value of about 0.02 peak-to-peak for the full energy species.

The beam neutralization fraction depends on the beam energy, neutralizer gas line density, and the species mix [2]. The neutralization fraction is plotted as a function of acceleration voltage using the measured species mix with a neutralizer gas line density of $1 \times 10^{16}$ particles $/ \mathrm{cm}^{2}$ (see Fig. 9). Also plotted on this figure is the neutralization fraction using the former estimated species mix of $0.7,0.2$, and 0.1 . At $80 \mathrm{keV}$, the neutralization fraction is $4 \%$ lower than the previous estimate. The injected beam power is linearly proportional to the neutralization fraction, thus at $80 \mathrm{keV}$ the injected power would also be $4 \%$ less than our previous estimate.

\section{CONCLUSION}

The ion source operational parameters of arc power, beam energy, perveance, and gas flow into both the source and the neutralizer were varied. Of these param-

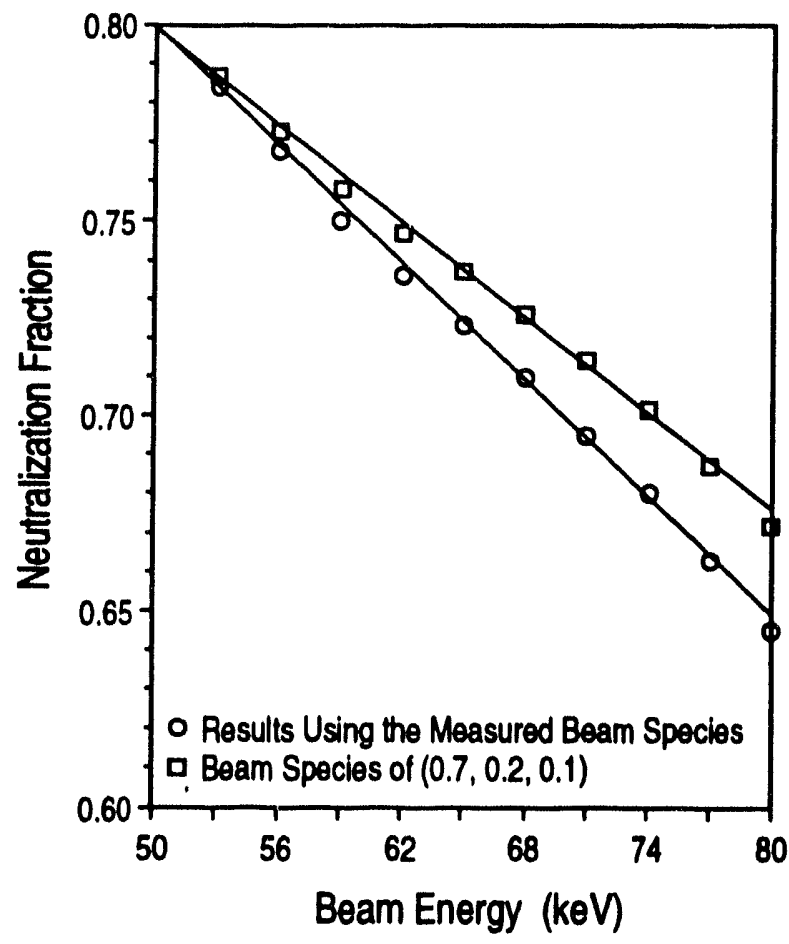

Fia. 9. Neutralization fraction as calculated for a fixed beam species of $0.7,0.2,0.1$ and as calculated for the measured beam species.

eters, the arc power has the strongest effect on the beam species. However, the gas flow rate also has a small effect beyond what the arc power would suggest. The beam species also has an oscillatory time variation of about $4 \mathrm{~Hz}$. The beam species measurements in the drift duct, being the same as those found in the neutralizer, verifies that the use of the thick target approximation is valid.

\section{REFERENCES}

[1] C.F. Burrell, W.S. Cooper, R.R. Smith, and W.F. Steele, "Doppler ahifted apectroncopy of powerful neutral beams," Rev. Sci. Instrum., vol. 61, pp. 14511-1462, 1880.

[2] J. Kim and H.H. Heselton, "Analyais of particle speciea evo lution in neutral beam injection lines," ORNL/TM-6302. Ouk Ridge, TN: Oak Ridge National Laboratory, 1978. 

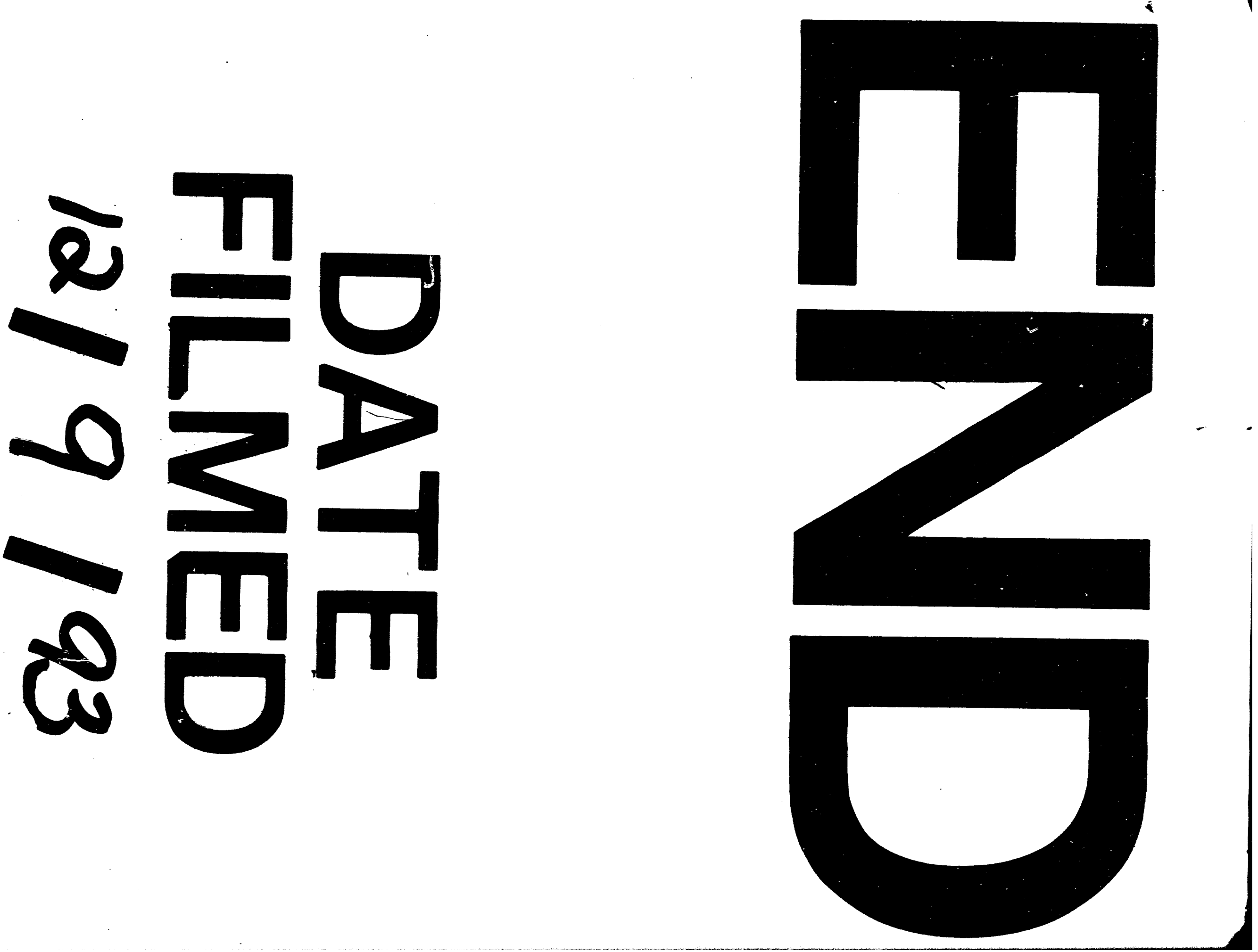
